\title{
Long Non-coding RNA: Insight Into Mechanisms of Alzheimer's Disease
}

\author{
Zhen Lan ${ }^{1}$, Yanting Chen ${ }^{2}$, Jiali Jin ${ }^{2}$, Yun $\mathrm{Xu}^{1,2,3,4,5}$ and Xiaolei Zhu ${ }^{1,2,3,4,5 *}$ \\ ${ }^{1}$ Department of Neurology, Nanjing Drum Tower Hospital, Clinical College of Nanjing Medical University, Nanjing, China, ${ }^{2}$ The \\ State Key Laboratory of Pharmaceutical Biotechnology, Department of Neurology, the Affiliated Hospital of Nanjing University \\ Medical School, Nanjing Drum Tower Hospital, Nanjing University, Nanjing, China, ${ }^{3}$ Institute of Brain Sciences, Nanjing \\ University, Nanjing, China, ${ }^{4}$ Jiangsu Key Laboratory for Molecular Medicine, Medical School of Nanjing University, Nanjing, \\ China, ${ }^{5}$ Nanjing Neuropsychiatry Clinic Medical Center, Nanjing, China
}

\section{OPEN ACCESS}

Edited by:

Ling-Qiang Zhu,

Huazhong University of Science and

Technology, China

Reviewed by:

Jin-Tai Yu,

University of California, San Francisco,

United States

Ping Zheng,

Fudan University, China

${ }^{*}$ Correspondence:

Xiaolei Zhu

zhuquelee@126.com

Specialty section:

This article was submitted to Molecular Signalling and Pathways, a section of the journal

Frontiers in Molecular Neuroscience

Received: 23 November 2021

Accepted: 22 December 2021

Published: 14 January 2022

Citation:

Lan Z, Chen Y, Jin J, Xu Y and Zhu X (2022) Long Non-coding RNA: Insight Into Mechanisms of Alzheimer's

Disease.

Front. Mol. Neurosci. 14:821002. doi: 10.3389/fnmol.2021.821002
Alzheimer's disease (AD), a heterogeneous neurodegenerative disorder, is the most common cause of dementia accounting for an estimated $60-80 \%$ of cases. The pathogenesis of $A D$ remains unclear, and no curative treatment is available so far. Increasing evidence has revealed a vital role of non-coding RNAs (ncRNAs), especially long non-coding RNAs (IncRNAs), in AD. LncRNAs contribute to the pathogenesis of $A D$ via modulating amyloid production, Tau hyperphosphorylation, mitochondrial dysfunction, oxidative stress, synaptic impairment and neuroinflammation. This review describes the biological functions and mechanisms of IncRNAs in AD, indicating that IncRNAs may provide potential therapeutic targets for the diagnosis and treatment of AD.

Keywords: long non-coding RNA, Alzheimer's disease, amyloid beta, tau phosphorylation, mitochondrial dysfunction, oxidative stress, synaptic dynamics, biomarker

\section{INTRODUCTION}

Alzheimer's disease (AD), a main cause of dementia and one of the most costly and lethal diseases (2021), is clinically characterized by progressive memory deterioration or other cognitive dysfunction, which ultimately needs full-time medical care. A cross-sectional study has shown that the overall prevalence of dementia achieves $6.0 \%$ in 2020 (3.9\% for AD), representing 15.07 million individuals aged over 60 years suffered dementia in China (Jia et al., 2020). Moreover, dementia has become the second largest cause of death in individuals aged more than 70 years after ischemic heart disease (Collaborators, 2019). AD is generally divided into two groups, namely the late onset of $\mathrm{AD}$ (LOAD) and the early onset of $\mathrm{AD}$ (EOAD). EOAD, also called familial AD, is closely correlated to mutations in amyloid precursor protein (APP) and the presenilin1/2 genes. The mutations lead to the dysfunction of APP processing and induce the excessive production of amyloid-beta $(A \beta)$. However, these genes account only for near $11 \%$ of EOAD and $0.6 \%$ of all cases of $\mathrm{AD}$ (Karch and Goate, 2015). LOAD, also called sporadic AD, is the majority of $\mathrm{AD}$ cases. The most well-known genes correlating with LOAD are apolipoprotein genotype $\mathrm{E} 4$ (APOE4) and triggering receptor expressed on myeloid cells 2 gene (TREM2) (Ulland and Colonna, 2018; Zhao et al., 2018).

With the recent advancement of transcriptome-wide profiling approach, numerous of non-coding RNAs (ncRNAs) have been identified. The long non-coding RNAs (lncRNAs), which are long transcripts ( $>200$ nucleotides in length) without apparent protein-coding capacity, have received increasing attention and are expected to be novel epigenetic regulators of gene expression at transcriptional and post-transcriptional levels (Mercer et al., 2009; Briggs et al., 2015; Zhang et al., 2019b; Karakas and Ozpolat, 2021). LncRNAs modulate chromatin functions by interaction with DNA, RNA and protein, and regulate the transcription of target genes in cis or in trans in 
the nucleus. In addition, lncRNAs function as miRNA sponges to suppress the miRNA availability to mRNAs in the cytosol (Statello et al., 2021). LncRNAs are widely expressed in brains and affect the proliferation, survival, metabolism and differentiation of neuronal cells, which is considered to contribute to the pathogenesis of AD (Wu et al., 2013). Mounting evidence has shown that lncRNAs are aberrantly expressed in $\mathrm{AD}$ progression, and modulate $A \beta$ plague formation, tau hyperphosphorylation, neuroinflammation and neuronal apoptosis (Luo and Chen, 2016; Zhou et al., 2021). However, the underlying mechanisms of lncRNAs in AD have not yet been elucidated. Herein, we will summarize the well-characterized lncRNAs in AD (Figure 1), highlighting their potential roles in the disease pathogenesis.

\section{LNCRNA AND A $\beta$ ACCUMULATION}

\section{$A \beta$ and $A D$}

Although the causality between $\mathrm{A} \beta$ and $\mathrm{AD}$ remains controversial, it is generally considered that $A \beta$ may be the trigger of $\mathrm{AD}$ pathogenesis. In the amyloidogenic pathway, $\mathrm{A} \beta$ is produced through sequential cleavage of APP by $\beta$-secretase $(\beta$-site APP cleaving enzyme $1, \mathrm{BACE}-1)$ and $\gamma$-secretase to produce $A \beta_{1-42}$. In non-amyloidogenic pathway, APP is cleaved by $\alpha$-secretase and $\gamma$-secretase to produce secreted amyloid precursor protein $\alpha(\mathrm{sAPP} \alpha), \mathrm{p} 3$ and APP intracellular domain (AICD) (Morris et al., 2014; Soria Lopez et al., 2019). A $\beta$ oligomers may trigger secondary or downstream events, such as the hyperphosphorylation of tau, synapse dysfunction and loss, inflammation, oxidative stress, and excitotoxicity, while $\mathrm{A} \beta$ plaques alone are not responsible for memory impairments observed in AD (Thal and Fandrich, 2015; Scheltens et al., 2016). Interestingly, recent research shows $A \beta$ may work as an anti-microbial peptide and therefore potentially acts to combat infiltrating infectious agents (Moir et al., 2018). On June 7, 2021, aducanumab, a monoclonal antibody targeting amyloid protein, is approved to treat $\mathrm{AD}$ by the US Food

Abbreviations: AD, Alzheimer's disease; ncRNAs, non-coding RNAs; lncRNAs, long non-coding RNAs; LOAD, late onset of $\mathrm{AD}$; EOAD, the early onset of AD; APP, amyloid precursor protein; A $\beta$, beta amyloid; APOE4, apolipoprotein genotype E4; TREM2, triggering receptor expressed on myeloid cells 2 gene; BACE1-AS, $\beta$-site APP cleaving enzyme-1 antisense; $\operatorname{sAPP} \alpha$, secreted amyloid precursor protein $\alpha$; AICD, APP intracellular domain; FDA, Food and Drug Administration; CSF, Cerebrospinal Fluid; BDNF-AS, brain-derived neurotrophic factor antisense; UTRs, untranslated regions; SORL1, Sortilin-related receptor 1; TGN, trans-Golgi network; GPR51, G-protein-coupled receptor 51 gene; BC200, brain cytoplasmic 200; FMRP, fragile X syndrome protein; NDM29, neuroblastoma differentiation marker 29; MAP, microtubule-associated proteins; MAPT, microtubule-associated protein tau; PHF, paired helical filaments; NFTs, neurofibrillary tangle; NEAT1, nuclear paraspeckles assembly transcript 1; MTs, microtubules; FZD3, Frizzled Class Receptor 3; ceRNA, competing endogenous RNA; MCI, Mild Cognitive Impairment; eIF4A, eukaryotic initiation factor 4A; SYNCRIP, synaptotagmin binding cytoplasmic RNA interacting protein; PABP, poly (A)-binding protein; MEN1, multiple endocrine neoplasia type 1; EBF3AS, Early B cell factor 3 antisense RNA; NAT-Rad18, natural antisense transcript against Rad18; MALAT1, metastasis-associated lung adenocarcinoma transcript 1; TUG1, taurine upregulated gene 1; WY1-AS, Wilms' tumor 1; GDNFOS, glial cell line-derived neurotrophic factor opposite strand; XIST, X-inactive specific transcript; SNHG1, small nucleolar RNA host gene 1; RPPH1, Ribonuclease P RNA component H1; lnc-ANRIL, lncRNA antisense non-coding RNA in the INK4 locus.

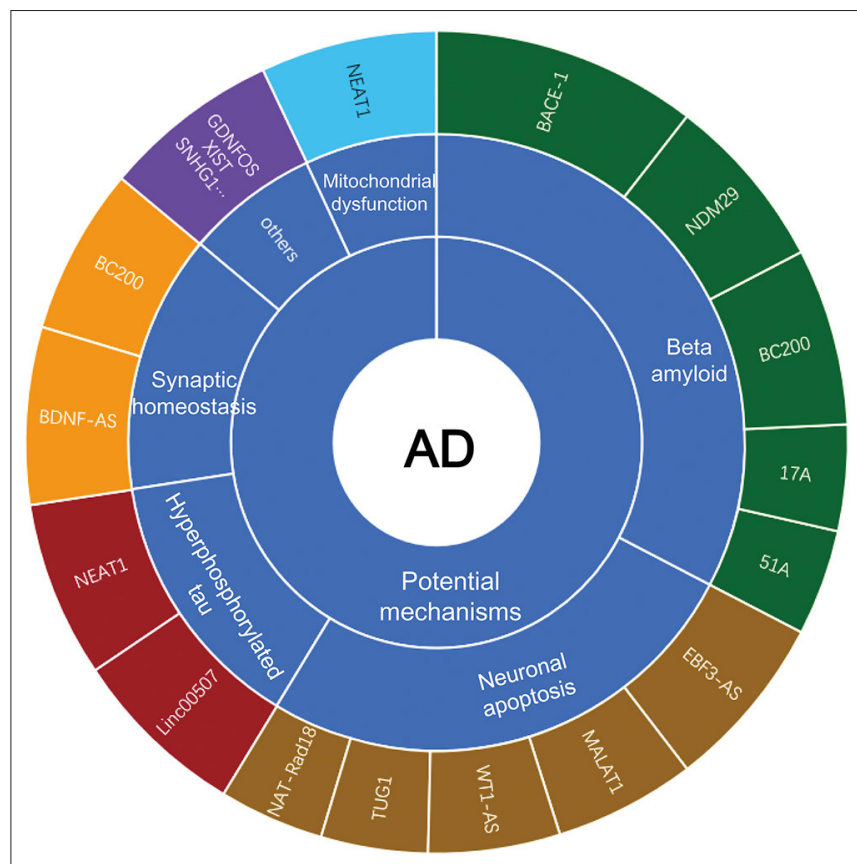

FIGURE 1 | LncRNAs in the mechanisms of AD.

and Drug Administration (FDA), which has sparked global debate, and further clinical trials are needed in the future (Alexander et al., 2021; Kuller and Lopez, 2021; Mullard, 2021).

\section{Beta-Site Amyloid Precursor Protein Cleaving Enzyme 1 Antisense Transcript Promotes A $\beta$ Production}

BACE1-AS is a conserved $2 \mathrm{~KB}$ non-coding antisense transcript that is transcribed from the antisense strand of the BACE1 gene locus on chromosome 11 (11q23. 3), and includes 104 nucleotides of full complementarity to human BACE1 mRNA (Faghihi et al., 2008; Kandalepas and Vassar, 2014). BACE1AS promotes BACE1 expression at both mRNA and protein levels, which enhances APP cleavage and alters the pattern of A $\beta$ aggregation (Li et al., 2019; Zeng et al., 2019). BACE1AS is upregulated in peripheral blood samples and brain regions including cerebellum, hippocampus and entorhinal cortex in AD patients (Faghihi et al., 2008; Fotuhi et al., 2019). Interestingly, the accumulation of $\mathrm{A} \beta_{1-42}$ further increases BACE1-AS expression, driving APP processing cascade in a feed-forward manner (Faghihi et al., 2008; Li et al., 2019). The neuronal RNA-binding protein $\mathrm{HuD}$ interacts with BACE1AS and increases its level, and subsequently promotes BACE1 expression and $\mathrm{A} \beta$ production (Kang et al., 2014). Cellular stimuli, including serum starvation, $\mathrm{A} \beta_{42}$ and $\mathrm{H}_{2} \mathrm{O}_{2}$ treatment, induce the upregulation of BACE1-AS under high glucose concentration (Boland et al., 2008; Faghihi et al., 2008; Liu et al., 2014). Knockdown of BACE1-AS by siRNA promotes the survival of primary neurons, and improves learning and 
memory functions of $\mathrm{AD}$ mice through inhibiting the expression of BACE1, APP and p-tau (Zhang et al., 2018b; Li et al., 2019).

\section{A Enhances $A \beta$ Formation}

LncRNA 51A maps in antisense configuration to the sortilinrelated receptor 1 (SORL1) gene, which induces a splicing shift of SORL1 from the synthesis of SORL1 variant A to an alternatively spliced protein form. SORL1 participates in the trafficking of APP through endocytic and secretory compartments (Willnow et al., 2010; Barthelson et al., 2020), and decreased SORL1 shifts APP from the retromer-recycling endosome pathway to the $\beta$-secretase cleavage pathway, leading to increased production and accumulation of $\mathrm{A} \beta$ (Sager et al., 2007; Verheijen et al., 2016). Recent studies reveal that $51 \mathrm{~A}$ is increased in the plasma and brains of $\mathrm{AD}$ patients compared that in controls, and indicate a negative correlation with the Mini-Mental State Examination (MMSE) scores (Luo and Chen, 2016; Garofalo et al., 2021).

\section{A Increases the Ratio of $A \beta_{x-42}$ vs. $A \beta_{x-40}$} LncRNA $17 \mathrm{~A}$ is a 159 nucleotides lncRNA synthesized by RNA polymerase III, and localizes to intron 3 of the human Gprotein-coupled receptor 51 gene (GPR51, GABA B2 receptor). The synthesis of $17 \mathrm{~A}$ leads to the maturation of GABAB R2 mRNA, which induces alternative GPR51 splicing and eventually impairs GABA B-mediated signaling. The level of $17 \mathrm{~A}$ is increased in the cerebral tissues derived from $\mathrm{AD}$ patients with an increased ratio of $A \beta_{x-42}$ vs. $A \beta_{x-40}$ (Massone et al., 2011). Overexpression of 17A in cultured neuronal cells amplifies the $A \beta_{42}$ to $A \beta_{40}$ ratio and promotes apoptosis (Wang et al., 2019b). All these data indicate that 17A overexpression may lead to an altered $A \beta$ secretion and play a vital role in $\mathrm{AD}$ progression.

\section{Brain Cytoplasmic 200 Promotes A $\beta$ Accumulation}

BC200 is a polyadenylated 200 nucleotides primate neuronspecific ncRNA that is transcribed by RNA polymerase III. BC200 acts as a local translational modulator by inhibiting translation in postsynaptic dendritic microdomains, which eventually maintains the plasticity of neuron. BC200 is upregulated in specific brain areas and is increased with disease progression in $\mathrm{AD}$, while it shows a steady decline in normal aging (Sosińska et al., 2015). Moreover, the overexpression of BC200 in $\mathrm{AD}$ is accompanied with distribution changes, including dendritic mislocalization of the transcript and accumulation of BC200 in the perikaryon (Sosińska et al., 2015; Shin et al., 2017), which has been proposed to be a starting point for the neurodegenerative changes, and eventually leads to $\mathrm{A} \beta$ production and amyloid deposition. In addition, $\mathrm{BC} 1$, a potential analog of $\mathrm{BC} 200$ in mice, induces APP mRNA translation through fragile $\mathrm{X}$ syndrome protein (FMRP), and the dysfunction of $\mathrm{BC} 1$ or $\mathrm{BC} 1-\mathrm{FMRP}$ association in $\mathrm{AD}$ mice impedes the aggregation of $\mathrm{A} \beta$ in the brain and protects against spatial learning and memory deficits (Mus et al., 2007).

\section{Neuroblastoma Differentiation Marker 29 Promotes A $\beta$ Secretion}

NDM29 is a lncRNA transcribed by RNA Pol III, and promotes neuroblastoma cell differentiation to a non-malignant neuronlike phenotype (Castelnuovo et al., 2010; Zhang et al., 2018a). NDM29 is upregulated in postmortem cerebral cortex from AD patients (Massone et al., 2012). NDM29 overexpression promotes the amyloidogenic processing of APP and leads to the increase of $\mathrm{A} \beta$ secretion and $\mathrm{A} \beta_{\mathrm{x}-42} / \mathrm{A} \beta_{\mathrm{x}-40}$ ratio (Massone et al., 2012).

\section{LNCRNA AND TAU HYPERPHOSPHORYLATION}

\section{Tau Hyperphosphorylation and AD}

Tau protein is encoded by the microtubule-associated protein tau (MAPT) gene that is located on chromosome 17 in human and chromosome 11 in mice (Andreadis, 2006; Barbier et al., 2019), and plays a pivotal role in binding and stabilizing microtubules by promoting tubulin assembly to regulate the function of neurons. The abnormal hyperphosphorylation of tau alters its charge and conformation and exposes the microtubule-binding domain, leading to self-oligomerization of tau protein and forming the paired helical filaments (PHF). The aggregation of tau and PHF eventually results in the formation of neurofibrillary tangles (NFTs) (Iqbal et al., 2016; Duan et al., 2017; Guo et al., 2017). Beyond hyperphosphorylation, tau protein is also post-translationally modified through truncation, glycosylation, glycation, ubiquitination, nitration, methylation, lipoperoxidation, sumoylation, and acetylation, all of which are involved in the etiology of $\mathrm{AD}$ and other tauopathies (Iqbal et al., 2016). On the other hand, tau phosphorylation is regulated by a balance between phosphatase activity and tau kinase (Massone et al., 2012; Martin et al., 2013a). The number of NFTs rather than $A \beta$ are correlated with the severity of cognitive impairment in $\mathrm{AD}$ patients (Giannakopoulos et al., 2003). Moreover, the distribution and accumulation of tau within synapse impairs synaptic transport and signaling pathways, leading to dysfunction and even loss of synapses in AD patients (Pooler et al., 2014; Dejanovic et al., 2018; John and Reddy, 2021). Similarly, tau oligomers are toxic to synapses and can cause synaptic impairment prior to the NFTs (Dejanovic et al., 2018). Notably, there is an intense crosstalk between $A \beta$ and tau. $\mathrm{A} \beta$ exerts its toxicity at least in part through tau and the $A \beta$ dependent pathologies can be greatly amplified by tau expression (Bloom, 2014; Nisbet et al., 2015). Removing endogenous tau prevents $A \beta$-associated cognitive impairments (Guerrero-Muñoz et al., 2015). A $\beta$-induced upregulation of intracellular calcium levels is a key upstream event for the formation of tauopathy and dislocation in the dendritic compartment (Bloom, 2014; Zempel and Mandelkow, 2015). Furthermore, pyroglutamylated $A \beta$, an important form of $A \beta$, induces tau-dependent toxicity and propagates in a prion-like manner (Nussbaum et al., 2012). 


\section{Nuclear Paraspeckles Assembly Transcript 1 Induces Tau Dephosphorylation}

NEAT1 is vital for nuclear paraspeckles, and it regulates nuclear bodies, chromatin remodeling, microtubules (MTs) stability and gene expression (Martin et al., 2013b). Recent studies have demonstrated that NEAT1 is correlated to neuronal loss and neurodegenerative disorders (Lo et al., 2016; Sunwoo et al., 2017). Knockdown of NEAT1 increases the expression of p-tau and dysfunction of MTs through Frizzled Class Receptor 3 (FZD3)/CSK3 $\beta / p$-tau pathway (Kickstein et al., 2010). Interestingly, metformin increases NEAT1 expression, and leads to decreased FZD3 expression and dephosphorylation of tau (Zhong et al., 2017). Additionally, NEAT1 modulates $A \beta$ via regulating miR-124/BACE1 axis (Zhao et al., 2020b).

\section{Linc00507 Induces Tau Hyperphosphorylation}

Linc00507, first described in the Mammalian Gene Collection Program, is expressed in a cortex-specific manner in nonhuman primates and humans (Strausberg et al., 2002; Ransohoff et al., 2018). Linc00507 is upregulated in the hippocampus and cerebral cortex of APP/PS1 mice, which subsequently triggers the $\mathrm{p} 25 / \mathrm{p} 35 / \mathrm{GSK} 3 \beta$ activation and leads to tau-pathology. In addition, linc00507 functions as an endogenously competing RNA (ceRNA) that directly binds to miR-181c-5p, inducing the upregulation of MAPT and tau tubulin kinase 1 (TTBK1) (Strausberg et al., 2002; Mills et al., 2016).

\section{LNCRNA AND LOSS OF SYNAPTIC HOMEOSTASIS}

\section{Loss of Synaptic Homeostasis and AD}

An analysis of post-mortem brain tissues from AD patients has revealed significant synapse loss (Henstridge et al., 2015; de Wilde et al., 2016). Restoring excitatory synaptic transmission in the hippocampus can effectively ameliorate the cognitive deficits in animal models with AD (Nisticò et al., 2012). The synaptic pathology correlates with clinical manifestations of $\mathrm{AD}$ and parallels the cognitive decline (Selkoe, 2002; Kashyap et al., 2019). In addition, dramatic synaptic loss is the first indicator of $\mathrm{AD}$ progression even in the earliest stages of $\mathrm{AD}$. Increasing evidence reveals that synaptic dysfunction may be due to soluble $A \beta$, phosphorylated tau accumulation and mitochondrial free radicals at synapses (John and Reddy, 2021; Pereira et al., 2021). The physiological levels of $A \beta$ may enhance neuronal activity by presynaptic potentiation and further facilitate $A \beta$ production, and ultimately induces negative postsynaptic regulation of excitatory synaptic transmission (Palop and Mucke, 2010). However, excessive A $\beta$ may lead to the dysfunction of pre-synapses consisting of axonal transport, synaptic vesicle cycling and neurotransmitter release. The interaction of $A \beta$ oligomers and postsynaptic compartment of excitatory synapses with high affinity leads to synaptic plasticity impairment (Selkoe, 2002; Palop and Mucke, 2010; Chen et al., 2019). The abnormal accumulation and mislocalization of tau disrupts the microtubule-based cellular transport and impedes the trafficking of essential cargo, leading to decreased mitochondrion-dependent ATP production, calcium buffering and synapse loss (Forner et al., 2017; John and Reddy, 2021). In addition, ApoE and its receptor regulate synaptic functions at both pre- and postsynaptic sites, amongst which ApoE4 induces neuronal dysfunction at the earliest stages of $\mathrm{AD}$ (Lane-Donovan and Herz, 2017; Zhao et al., 2020a). Furthermore, the dysfunction of AMPA receptors (AMPAR) trafficking impairs neuronal circuit formation and causes long-term depression, which contributes to the symptoms of AD (Jurado, 2017; Ma et al., 2020).

\section{BC200 Impairs Synaptic Functions}

BC200 is selectively expressed in neurons and delivered to the dendrites to regulate the synthesis of local proteins (Yan et al., 2020), and maintains the long-term plasticity (Muslimov et al., 1997). The mislocalization and overexpression of BC200 contributes to dendrites impairment in $\mathrm{AD}$. The level of BC200 in affected brain areas closely correlates with the synaptic impairment and the severity of AD (Muddashetty et al., 2002; Bassell and Twiss, 2006). In addition, the somatodendritic distribution of $\mathrm{BC} 200$ is altered in severe AD (Muddashetty et al., 2002; Bassell and Twiss, 2006). Furthermore, BC200 binds to eukaryotic initiation factor 4A (eIF4A) and other RNA-binding proteins to regulate the levels of post-synaptic dendritic microdomains, including FMRP, synaptotagmin binding cytoplasmic RNA interacting protein (SYNCRIP) and poly (A)-binding protein (PABP) (Zalfa et al., 2005; Mus et al., 2007; Duning et al., 2008).

\section{BDNF-AS Damages Synaptic Plasticity}

Brain-derived neurotrophic factor (BDNF) plays a crucial role in neuronal survival and synaptic plasticity and promotes the synapse growth, which consequently regulates learning and memory function (Lu et al., 2014; Petukhova et al., 2019). BDNFAS is a conserved non-coding antisense RNA transcript, and modulates synaptic structure and functions via interacting with BDNF mRNA (Alsina et al., 2001). BDNF is decreased in most neurodegenerative disorders (Ji et al., 2010), however, some studies show increased BDNF in the post-mortem brain tissue with AD (Ventriglia et al., 2013). BDNF-AS forms an in vivo RNA-RNA duplex with BDNF mRNA and decreases the protein level of BDNF, while BDNF-AS inhibition upregulates the level of BDNF (Alsina et al., 2001). Moreover, BDNF-AS downregulates the level of BDNF mRNA through interfering chromatin at its locus (Alsina et al., 2001).

\section{LNCRNA AND MITOCHONDRIAL DYSFUNCTION}

\section{Mitochondrial Dysfunction and AD}

Mitochondrial dysfunction is revealed as one of the earliest features of AD (Serý et al., 2013). The brain consumes nearly $20 \%$ of the total basal oxygen budget to support ATP demands, and it is susceptible to oxidative stress and energy shortage due to mitochondrial dysfunction (Galluzzi et al., 2012; Perez Ortiz and Swerdlow, 2019). Several studies suggest that bioenergetic deficits precede the accumulation of $A \beta$ and tau, and are exacerbated 
with these aggregated proteins (Galluzzi et al., 2012; Tyumentsev et al., 2018). Moreover, it is found that restoration of the activity of phosphatase and tensin homolog (PTEN) induced putative kinase 1 (PINK1) improves the cognitive functions and lowers $\mathrm{A} \beta$ production in $\mathrm{AD}$ mice (Tyumentsev et al., 2018; Lim et al., 2020).

\section{Nuclear Enriched Abundant Transcript 1 Induces Mitochondrial Impairment}

NEAT1 is a lncRNA transcribed from the multiple endocrine neoplasia type 1 (MEN1) gene, known as a scaffold for paraspeckles. NEAT1 plays a vital role in the formation and maintenance of paraspeckles (Cadonic et al., 2016). NEAT1 is upregulated during aging in the APP/PS1 transgenic mouse model and in the temporal cortex and hippocampus of AD mice (Liu et al., 2014; Huang et al., 2020). Knockdown of NEAT1 ameliorates cognitive impairments and improves hippocampal memory formation, and its overexpression exacerbates the progression of $\mathrm{AD}$ pathology and cognitive impairment in $\mathrm{AD}$ mice (Zhou et al., 2018b; Cao et al., 2019). The underlying mechanisms of NEAT1 in AD remain undefined. Recent studies show that NEAT1 interferes with mitochondria through PINK1 in AD models (Zhou et al., 2018b). NEAT1 promotes the degradation of PINK1 and impairs PINK1-dependent autophagy, leading to the dysfunction of autophagy signaling and inducing the amyloid accumulation and mitochondrial impairment (Zhou et al., 2018b; Lim et al., 2020). In addition, NEAT1 regulates $\mathrm{A} \beta$ accumulation in $\mathrm{AD}$ mice through interacting with miR-124 and miR-107, and knockdown of NEAT1 attenuates A $\beta$-induced neuronal damage (Zhou et al., 2018b; Butler et al., 2019; Ke et al., 2019).

\section{LNCRNA AND NEURONAL APOPTOSIS}

\section{Neuronal Apoptosis and AD}

Neuronal apoptosis plays an important role in central nervous system, and the perturbation of apoptosis is involved in the neurodegenerative diseases including $\mathrm{AD}$ ( $\mathrm{Gu}$ et al., 2018). Caspases act as both initiator and executor of apoptosis, and at least 7 caspases have been involved in AD including caspase-1, $2,3,6,8,9$, and 12. For instance, the level of caspase-1 mRNA is upregulated in AD brain extracts (Qian et al., 2015). The deficiency of caspase-2 protects several neuronal subtypes from $\mathrm{A} \beta$-induced apoptotic death in vitro (Desjardins and Ledoux, 1998), and caspase-3 is increased in AD brain and is activated in A $\beta$-treated neuronal cultures (Gervais et al., 1999). Previous reports have shown that many DNA fragmentation in postmortem brains of $\mathrm{AD}$ patients, which indicates the activity of apoptosis in AD (Lassmann et al., 1995). All these data suggest that neuronal apoptosis dysregulation mediates the pathogenesis of $\mathrm{AD}$.

\section{Early B Cell Factor 3 Antisense RNA Induces Neuronal Apoptosis}

EBF3-AS, a 2-exon RNA transcribed from the opposite strand of the protein-coding gene Early B cell factor 3 (EBF3), is abundantly expressed in brain (Zhao et al., 2019). EBF3 is thought to be a target gene of EBF3-AS and is potentially associated with age in LOAD (Magistri et al., 2015). Previous studies have revealed that EBF3 homologs are essential for survival and dysfunction of EBF3 correlates to a range of nervous system developmental defects including perturbation of neuronal development and migration (Belbin et al., 2011). EBF3-AS and $\mathrm{EBF} 3$ are upregulated in the hippocampus of $\mathrm{AD}$ mice, and knockdown of EBF3-AS and EBF3 inhibits the apoptosis induced by $A \beta$ (Chao et al., 2017). These results suggest that EBF3-AS induces neuronal apoptosis in $\mathrm{AD}$, supporting EBF3-AS as a new target for AD treatment.

\section{Natural Antisense Transcript Against Rad18 Promotes Neuronal Apoptosis}

NAT-Rad18, with a length of 509 nucleotides, plays a crucial role in DNA repair, and is directly responsible for the specific mono-ubiquitylation of the polymerase adapter PCNA (Lloyd et al., 2006; Parenti et al., 2007). NAT-Rad18 is universally expressed in the brain, especially in the cerebellum, brainstem, spinal cord, olfactory bulb, cortex, hippocampus and striatum (Flores et al., 2018). The upregulation of NATRad18 renders cells more sensitive to a wide spectrum of DNAdamaging agents (Harvey et al., 2004), which may be part of a complex transcriptional and post-transcriptional genomic program underlying $A \beta$-neurotoxicity.

\section{Metastasis-Associated Lung Adenocarcinoma Transcript 1 Reduces Neuronal Apoptosis}

MALAT1 is a long intergenic non-coding RNA that is located on chromosome 11q13 and consists of 8,828 nucleotides (Tateishi et al., 2000). Emerging evidence suggests a neuroprotective function of MALAT1 via inhibiting neuroinflammation. MALAT1 is decreased in A $\beta 1-42$ treated neurons, and induces the neurite outgrowth (Ji et al., 2003; Ma et al., 2019). Overexpression of MALAT1 reduces neuronal apoptosis and alleviates neuronal injury (Zhuang et al., 2020), and knockdown of MALAT1 promotes neuronal apoptosis and represses neurite growth (Ji et al., 2003). Additionally, MALAT1 modulates miR-125b expression and consequently suppresses neuronal apoptosis and inflammation (Ji et al., 2003; Ma et al., 2019).

\section{Taurine Upregulated Gene 1 Facilitates Neuronal Apoptosis}

TUG1 is a novel lncRNA with $6.7-\mathrm{kb}$ nucleotides located on the chromosome 22q12, and is involved in neuronal apoptosis, proliferation, cell cycle and metastasis (Li et al., 2020a). Recent studies have revealed the important role of TUG1 in AD through controlling the neuronal apoptosis. TUG1 silencing decreases cellular apoptosis in $A \beta_{25-35}$-treated hippocampal neurons, and consequently improves spatial learning and memory of AD mice (Guo et al., 2020). In addition, TUG1 acts as miR-15a sponge and regulates neuronal apoptosis via the proteolytic cleavage of crucial proteins (Guo et al., 2020; Li et al., 2020b). 
TABLE 1 | Potential IncRNA biomarkers in AD patients.

\begin{tabular}{|c|c|c|c|}
\hline Related IncRNA & Regions of AD patients & Biological function & References \\
\hline $\mathrm{BACE} 1-\mathrm{AS} \uparrow / \downarrow$ & Brain, plasma & $\begin{array}{l}\text { Upregulating BACE } 1 \text { mRNA stability; Altering } A \beta \text { aggregation pattern } \\
\text { increasing } A \beta \text { expression. }\end{array}$ & $\begin{array}{l}\text { Faghihi et al., 2008; Fotuhi et al., } \\
2019\end{array}$ \\
\hline NDM29个 & Cerebral cortex & $\begin{array}{l}\text { Promoting the cleavage activity of BACE and } \gamma \text {-secretase; Increasing } \\
A \beta \text { secretion and } A \beta_{x-42} / A \beta_{x-40} \text { ratio. }\end{array}$ & Massone et al., 2012 \\
\hline $51 \mathrm{~A} \uparrow$ & Cerebral cortex and plasma & Downregulating SORL1; Increasing production and accumulation of A $\beta$. & $\begin{array}{l}\text { Massone et al., 2011; Ciarlo et al., } \\
2013\end{array}$ \\
\hline $17 \mathrm{~A} \uparrow$ & Cerebral cortex & Impairing the GABAB signaling pathway & Massone et al., 2011 \\
\hline BC200个 & Cerebral cortex & $\begin{array}{l}\text { Inducing A } \beta \text { production and amyloid deposition; Maintaining the } \\
\text { long-term synapse plasticity }\end{array}$ & Mus et al., 2007 \\
\hline
\end{tabular}

The arrows next to IncRNA indicates up/down-regulation in $A D$ patients.

\section{Wilms Tumor 1 Homolog Antisense RNA Inhibits Neuronal Apoptosis}

WT1-AS, a lncRNA located on chromosome 11p13, is important in regulating transcription, apoptosis and RNA metabolism (Zhang et al., 2019a; Wu et al., 2021). WT1-AS is downregulated in $A \beta_{25-35}$ treated SH-SY5Y cells, and overexpression of WT1AS inhibits WT1 expression and reverses the deleterious effects of $A \beta_{25-35}$ (Toska and Roberts, 2014). In addition, WT1-AS inhibits apoptosis via reducing WT1 expression or suppressing miR-375 expression (Toska and Roberts, 2014).

\section{LNCRNA AND NEUROINFLAMMATION}

\section{Neuroinflammation and AD}

Neuroinflammation is a response to various stimuli and consists of glia cells, lymphocytes, monocytes and macrophages, which directly contributes to the pathogenesis and progression of $\mathrm{AD}$ (Maccioni et al., 2020). Neuroinflammation acts as a "doubleedged sword" in the central nerve system (Cortés et al., 2018; Maccioni et al., 2020). The balance between neuronal damage and inflammation is mainly regulated by glia cells (Maccioni et al., 2020). Microglia functions as resident phagocytes to dynamically monitor the environment, and contributes to the brain development and synaptic pruning (Frost and Schafer, 2016; Colonna and Butovsky, 2017). Astrocytes are shown to maintain brain homeostasis, protect neural circuits and repair injuries (Sofroniew and Vinters, 2010; Cai et al., 2017b). Dysfunction of astrocytes induces tau hyperphosphorylation and NFT formation and failure of $\mathrm{A} \beta$ clearance (Yan et al., 2013; Leyns and Holtzman, 2017). Moreover, astrocytes are the most important energy regulators in CSF, and astrocyte metabolic dysfunction is considered as an initiating factor in $\mathrm{AD}$ (Yan et al., 2013).

\section{Maternally Expressed Gene 3 Reduces Neuroinflammatory Injury}

MEG3 locates on chromosome 14 in humans and acts as a mediator in inflammation. MEG3 plays a key role in various biological processes including microglia activation and inflammatory response (Kobayashi et al., 2000; Meng et al., 2021). Upregulation of MEG3 inactivates astrocyte through inhibiting the PI3/Akt pathway, and improves the spatial memory in AD rats (Yi et al., 2019). MEG3 is also a direct target of miR-7a-5p, and overexpression of MEG3 reduces miR-7a-5p and promotes microglia activation (Meng et al., 2021).

\section{MALAT1 Attenuates Neuroinflammation}

Accumulating evidence indicates the neuroprotective and antiinflammatory role of MALAT1 in neurodegenerative diseases (Zhou et al., 2018a; Masoumi et al., 2019). MALAT1 inhibits the inflammation-associated miRNAs levels, and attenuates neuroinflammation in AD (Ma et al., 2019). MALAT1 is also decreased in $\mathrm{A} \beta_{1-42}$ treated cells and inhibits neuronal apoptosis (Ma et al., 2019).

\section{Other LncRNA With AD}

Glial cell line-derived neurotrophic factor (GDNF) is a neurotrophic peptide, and is known as a neurotropin to promote the survival and differentiation of midbrain dopaminergic neurons (Ledda et al., 2007; Airavaara et al., 2011). Glial cell line-derived neurotrophic factor opposite strand (GDNFOS) is a cis-natural antisense transcribed from the opposite strand of GDNF gene (Cortini et al., 2019). In patients with $\mathrm{AD}$, the level of mature GDNF is increased in CSF and decreased in serum, while GDNFOS1 is upregulated in cerebellum (Straten et al., 2009; Airavaara et al., 2011). MAGI2-AS3 is significantly increased in $A \beta_{25-35}$ induced neuronal cells and in $A D$ patients, and knockdown of MAGI2-AS3 attenuates neurotoxicity and neuroinflammation (Wang et al., 2020). LncRNA X-inactive specific transcript (XIST) is a functional lncRNA which plays an important role in the development and progression of many malignant tumors (Yi et al., 2019). The expression of XIST is significantly increased in $\mathrm{AD}$ models and silencing XIST negatively regulates the expression of miR-124 and promotes BACE1 expression (Du et al., 2017). Ribonuclease P RNA component H1 (RPPH1) is an RNA component of the RNase $\mathrm{P}$ ribonucleoprotein, which cleaves tRNA precursor molecules to generate the mature tRNA (Yue et al., 2020). Overexpression of RPPH1 increases the density of dendritic spine in hippocampal neuron (Cai et al., 2017a), which suggests a protective role of $\mathrm{RPPH} 1$ in the early stage of AD. Small nucleolar RNA host gene 1 (SNHG1) is upregulated in $\mathrm{A} \beta_{25-35}$ treated cells and knockdown of SNHG1 attenuates $A \beta_{25-35}$ induced mitochondrial dysfunction and cell apoptosis (Cai 
et al., 2017a; Wang et al., 2019a). Recent studies have shown that knockdown of the lncRNA antisense non-coding RNA in the INK4 locus (lnc-ANRIL) inhibits apoptosis and promotes neurite outgrowth in a cellular model of $\mathrm{AD}$ (Zhou et al., 2020).

\section{LncRNA in Clinical AD Management and Perspective}

LncRNAs are relatively stable, which indicates that the serum or CSF lncRNAs might be promising biomarkers and therapeutic targets for $\mathrm{AD}$ diagnosis and treatment (Table 1). The concentration of BACE1 in CSF and plasma shows a good diagnostic value in $\mathrm{AD}$ patients (Shen et al., 2018; Lopez-Font et al., 2019). Therapeutic strategies targeting BACE1 have been extensively developed but discontinued due to futility or safety reasons (Ghosh and Osswald, 2014; Hampel et al., 2021). BACE1-AS becomes an attractive biomarker for $\mathrm{AD}$, and the level of BACE1-AS is upregulated in the brain and plasma of AD patients (Faghihi et al., 2008; Feng et al., 2018) but significantly decreased in pre-AD cases (Fotuhi et al., 2019). Overexpression of NDM29 is observed in AD postmortem cerebral cortex samples (Massone et al., 2012). 51A is overexpressed in AD post-mortem samples and shows an active role in altering SORL1 expression in $\mathrm{AD}$ patients and a positive correlation with $\mathrm{A} \beta$ production compared with that in healthy controls (Ciarlo et al., 2013). 17A is upregulated in cerebral cortices in $\mathrm{AD}$ patients and is specifically overexpressed in $\mathrm{AD}$ patients rather than other neurodegenerative diseases (Massone et al., 2011). The level of BC200 in cortical areas is increased in brains from $\mathrm{AD}$ patients, and is reduced in normal aging individuals (Mus et al., 2007). However, it is also shown that the plasma levels of 17A, 51A and, BC200 are not significantly affected in $\mathrm{AD}$ patients compared with those in age-matched controls (Feng et al., 2018). These inconsistent results may be attributed to relative smaller sample size and different disease stages.

\section{REFERENCES}

(2021). 2021 Alzheimer's disease facts and figures. Alzheimers. Dement. 17, 327-406. doi: 10.1002/alz.12328

Airavaara, M., Pletnikova, O., Doyle, M. E., Zhang, Y. E., Troncoso, J. C., and Liu, Q. R. (2011). Identification of novel GDNF isoforms and cis-antisense GDNFOS gene and their regulation in human middle temporal gyrus of Alzheimer disease. J. Biol. Chem. 286, 45093-45102. doi: 10.1074/jbc.M111.310250

Alexander, G. C., Knopman, D. S., Emerson, S. S., Ovbiagele, B., Kryscio, R. J., Perlmutter, J. S., et al. (2021). Revisiting FDA approval of aducanumab. N. Engl. J. Med. 385, 769-771 doi: 10.1056/NEJMp2110468

Alsina, B., Vu, T., and Cohen-Cory, S. (2001). Visualizing synapse formation in arborizing optic axons in vivo: dynamics and modulation by BDNF. Nat. Neurosci. 4, 1093-1101. doi: 10.1038/nn735

Andreadis, A. (2006). Misregulation of tau alternative splicing in neurodegeneration and dementia. Prog. Mol. Subcell. Biol. 44, 89-107. doi: 10.1007/978-3-540-34449-0_5

Barbier, P., Zejneli, O., Martinho, M., Lasorsa, A., Belle, V., Smet-Nocca, C., et al. (2019). Role of tau as a microtubule-associated protein: structural and functional aspects. Front. Aging Neurosci. 11:204. doi: 10.3389/fnagi.2019. 00204
Larger-scale trials are needed to elucidate the lncRNA profile in $\mathrm{AD}$.

\section{CONCLUSION}

Up to now, numerous IncRNAs have been identified to be associated with $\mathrm{AD}$, but it is only a tip of the iceberg. LncRNAs play a critical role in the AD pathogenesis including amyloid production, Tau hyperphosphorylation, mitochondrial dysfunction, synaptic impairment and neuroinflammation. However, how lncRNAs function at molecular and cellular levels remains a huge challenge, and the biological characteristics and underlying mechanisms of lncRNAs in $\mathrm{AD}$ still need to be elucidated. Undoubtedly, further investigation of lncRNAs lights a new beacon for clinical diagnosis and treatment of AD.

\section{DATA AVAILABILITY STATEMENT}

The original contributions presented in the study are included in the article/supplementary material, and further inquiries can be directed to the corresponding author.

\section{AUTHOR CONTRIBUTIONS}

ZL, YC, JJ, YX, and XZ wrote the paper. All authors read and approved the final manuscript.

\section{FUNDING}

This research was supported by the National Nature Science Foundation of China (81971009, 81630028, and 81920108017), the Fundamental Research Funds for the Central Universities (021414380519), the Natural Science Foundation of Jiangsu Province (SBK2021021574), and the National Key Research and Development Program of China (2018YFC1704400).
Barthelson, K., Newman, M., and Lardelli, M. (2020). Sorting out the role of the sortilin-related receptor 1 in Alzheimer's disease. J. Alzheimers Dis. Rep. 4, 123-140. doi: 10.3233/ADR-200177

Bassell, G. J., and Twiss, J. L. (2006). RNA exodus to Israel: RNA controlling function in the far reaches of the neuron. Workshop on RNA control on neuronal function. EMBO Rep. 7, 31-35. doi: 10.1038/sj.embor.7400616

Belbin, O., Carrasquillo, M. M., Crump, M., Culley, O. J., Hunter, T. A., Ma, L., et al. (2011). Investigation of 15 of the top candidate genes for late-onset Alzheimer's disease. Hum. Genet. 129, 273-282. doi: 10.1007/s00439-010-0924-2

Bloom, G. S. (2014). Amyloid- $\beta$ and tau: the trigger and bullet in Alzheimer disease pathogenesis. JAMA Neurol. 71, 505-508. doi: 10.1001/jamaneurol.2013.5847

Boland, B., Kumar, A., Lee, S., Platt, F. M., Wegiel, J., Yu, W. H., et al. (2008). Autophagy induction and autophagosome clearance in neurons: relationship to autophagic pathology in Alzheimer's disease. J. Neurosci. 28, 6926-6937. doi: 10.1523/JNEUROSCI.0800-08.2008

Briggs, J. A., Wolvetang, E. J., Mattick, J. S., Rinn, J. L., and Barry, G. (2015). Mechanisms of long non-coding RNAs in mammalian nervous system development, plasticity, disease, and evolution. Neuron 88, 861-877. doi: 10.1016/j.neuron.2015.09.045

Butler, A. A., Johnston, D. R., Kaur, S., and Lubin, F. D. (2019). Long noncoding RNA NEAT1 mediates neuronal histone methylation and age-related memory impairment. Sci. Signal. 12:eaaw9277. doi: 10.1126/scisignal.aaw9277 
Cadonic, C., Sabbir, M. G., and Albensi, B. C. (2016). Mechanisms of mitochondrial dysfunction in Alzheimer's disease. Mol. Neurobiol. 53, 6078-6090. doi: 10.1007/s12035-015-9515-5

Cai, Y., Sun, Z., Jia, H., Luo, H., Ye, X., Wu, Q., et al. (2017a). Rpph1 upregulates CDC42 expression and promotes hippocampal neuron dendritic spine formation by competing with miR-330-5p. Front. Mol. Neurosci. 10:27. doi: $10.3389 /$ fnmol.2017.00027

Cai, Z., Wan, C. Q., and Liu, Z. (2017b). Astrocyte and Alzheimer's disease. J. Neurol. 264, 2068-2074. doi: 10.1007/s00415-017-8593-x

Cao, M., Li, H., Zhao, J., Cui, J., and Hu, G. (2019). Identification of age- and gender-associated long noncoding RNAs in the human brain with Alzheimer's disease. Neurobiol. Aging 81, 116-126. doi: 10.1016/j.neurobiolaging.2019.05.023

Castelnuovo, M., Massone, S., Tasso, R., Fiorino, G., Gatti, M., Robello, M., et al. (2010). An Alu-like RNA promotes cell differentiation and reduces malignancy of human neuroblastoma cells. FASEB J. 24, 4033-4046. doi: 10.1096/fj.10-157032

Chao, H. T., Davids, M., Burke, E., Pappas, J. G., Rosenfeld, J. A., McCarty, A. J., et al. (2017). A syndromic neurodevelopmental disorder caused by de novo variants in EBF3. Am. J. Hum. Genet. 100, 128-137. doi: 10.1016/j.ajhg.2016.11.018

Chen, Y., Fu, A. K. Y., and Ip, N. Y. (2019). Synaptic dysfunction in Alzheimer's disease: mechanisms and therapeutic strategies. Pharmacol. Ther. 195, 186-198. doi: 10.1016/j.pharmthera.2018.11.006

Ciarlo, E., Massone, S., Penna, I., Nizzari, M., Gigoni, A., Dieci, G., et al. (2013). An intronic ncRNA-dependent regulation of SORL1 expression affecting $\mathrm{A} \beta$ formation is upregulated in post-mortem Alzheimer's disease brain samples. Dis. Model. Mech. 6, 424-433. doi: 10.1242/d mm.009761

Collaborators, G. B. D. D. (2019). Global, regional, and national burden of Alzheimer's disease and other dementias, 1990-2016: a systematic analysis for the Global Burden of Disease Study 2016. Lancet Neurol. 18, 88-106. doi: 10.1016/S1474-4422(18)30403-4

Colonna, M., and Butovsky, O. (2017). Microglia function in the central nervous system during health and neurodegeneration. Annu. Rev. Immunol. 35, 441-468. doi: 10.1146/annurev-immunol-051116-052358

Cortés, N., Andrade, V., Guzmán-Martínez, L., Estrella, M., and Maccioni, R. B. (2018). Neuroimmune tau mechanisms: their role in the progression of neuronal degeneration. Int. J. Mol. Sci. 19:956. doi: 10.3390/ijms19040956

Cortini, F., Roma, F., and Villa, C. (2019). Emerging roles of long non-coding RNAs in the pathogenesis of Alzheimer's disease. Ageing Res. Rev. 50, 19-26. doi: 10.1016/j.arr.2019.01.001

de Wilde, M. C., Overk, C. R., Sijben, J. W., and Masliah, E. (2016). Meta-analysis of synaptic pathology in Alzheimer's disease reveals selective molecular vesicular machinery vulnerability. Alzheimers. Dement. 12, 633-644. doi: 10.1016/j.jalz.2015.12.005

Dejanovic, B., Huntley, M. A., De Mazière, A., Meilandt, W. J., Wu, T., Srinivasan, K., et al. (2018). Changes in the synaptic proteome in tauopathy and rescue of tau-induced synapse loss by C1q antibodies. Neuron100, 1322-1336.e1327. doi: 10.1016/j.neuron.2018.10.014

Desjardins, P., and Ledoux, S. (1998). Expression of ced-3 and ced-9 homologs in Alzheimer's disease cerebral cortex. Neurosci. Lett. 244, 69-72. doi: 10.1016/S0304-3940(98)00138-4

Du, Y., Weng, X. D., Wang, L., Liu, X. H., Zhu, H. C., Guo, J., et al. (2017). LncRNA XIST acts as a tumor suppressor in prostate cancer through sponging miR-23a to modulate RKIP expression. Oncotarget 8, 94358-94370. doi: 10.18632/oncotarget.21719

Duan, A. R., Jonasson, E. M., Alberico, E. O., Li, C., Scripture, J. P., Miller, R. A., et al. (2017). Interactions between tau and different conformations of tubulin: implications for tau function and mechanism. J. Mol. Biol. 429, 1424-1438. doi: 10.1016/j.jmb.2017.03.018

Duning, K., Buck, F., Barnekow, A., and Kremerskothen, J. (2008). SYNCRIP, a component of dendritically localized mRNPs, binds to the translation regulator BC200 RNA. J. Neurochem. 105, 351-359. doi: 10.1111/j.1471-4159.2007.05138.x

Faghihi, M. A., Modarresi, F., Khalil, A. M., Wood, D. E., Sahagan, B. G., Morgan, T. E., et al. (2008). Expression of a noncoding RNA is elevated in Alzheimer's disease and drives rapid feed-forward regulation of beta-secretase. Nat. Med. 14, 723-730. doi: 10.1038/nm1784

Feng, L., Liao, Y. T., He, J. C., Xie, C. L., Chen, S. Y., Fan, H. H., et al. (2018). Plasma long non-coding RNA BACE1 as a novel biomarker for diagnosis of Alzheimer disease. BMC Neurol. 18:4. doi: 10.1186/s12883-017-1008-x

Flores, J., Noël, A., Foveau, B., Lynham, J., Lecrux, C., and LeBlanc, A. C. (2018). Caspase-1 inhibition alleviates cognitive impairment and neuropathology in an Alzheimer's disease mouse model. Nat. Commun. 9:3916. doi: 10.1038/s41467-018-06449-x

Forner, S., Baglietto-Vargas, D., Martini, A. C., Trujillo-Estrada, L., and LaFerla, F. M. (2017). Synaptic impairment in Alzheimer's disease: a dysregulated symphony. Trends Neurosci. 40, 347-357. doi: 10.1016/j.tins.2017.04.002

Fotuhi, S. N., Khalaj-Kondori, M., Hoseinpour Feizi, M. A., and Talebi, M. (2019). Long non-coding RNA BACE1-AS may serve as an Alzheimer's disease blood-based biomarker. J. Mol. Neurosci. 69, 351-359. doi: 10.1007/s12031-019-01364-2

Frost, J. L., and Schafer, D. P. (2016). Microglia: architects of the developing nervous system. Trends Cell Biol. 26, 587-597. doi: 10.1016/j.tcb.2016.02.006

Galluzzi, L., Kepp, O., Trojel-Hansen, C., and Kroemer, G. (2012). Mitochondrial control of cellular life, stress, and death. Circ. Res. 111, 1198-1207. doi: 10.1161/CIRCRESAHA.112.268946

Garofalo, M., Pandini, C., Sproviero, D., Pansarasa, O., Cereda, C., and Gagliardi, S. (2021). Advances with long non-coding RNAs in Alzheimer's disease as peripheral biomarker. Genes 12:1124. doi: 10.3390/genes 12081124

Gervais, F. G., Xu, D., Robertson, G. S., Vaillancourt, J. P., Zhu, Y., Huang, J., et al. (1999). Involvement of caspases in proteolytic cleavage of Alzheimer's amyloidbeta precursor protein and amyloidogenic A beta peptide formation. Cell 97, 395-406. doi: 10.1016/S0092-8674(00)80748-5

Ghosh, A. K., and Osswald, H. L. (2014). BACE1 ( $\beta$-secretase) inhibitors for the treatment of Alzheimer's disease. Chem. Soc. Rev. 43, 6765-6813. doi: $10.1039 / \mathrm{C} 3 \mathrm{CS} 60460 \mathrm{H}$

Giannakopoulos, P., Herrmann, F. R., Bussière, T., Bouras, C., Kövari, E., Perl, D. P., et al. (2003). Tangle and neuron numbers, but not amyloid load, predict cognitive status in Alzheimer's disease. Neurology 60, 1495-1500. doi: 10.1212/01.WNL.0000063311.58879.01

Gu, C., Chen, C., Wu, R., Dong, T., Hu, X., Yao, Y., et al. (2018). Long noncoding RNA EBF3-AS promotes neuron apoptosis in Alzheimer's disease. DNA Cell Biol. 37, 220-226. doi: 10.1089/dna.2017.4012

Guerrero-Muñoz, M. J., Gerson, J., and Castillo-Carranza, D. L. (2015). Tau oligomers: the toxic player at synapses in Alzheimer's disease. Front. Cell. Neurosci. 9:464. doi: 10.3389/fncel.2015.00464

Guo, C., Qi, Y., Qu, J., Gai, L., Shi, Y., and Yuan, C. (2020). Pathophysiological functions of the lncRNA TUG1. Curr. Pharm. Des. 26, 688-700. doi: $10.2174 / 1381612826666191227154009$

Guo, T., Noble, W., and Hanger, D. P. (2017). Roles of tau protein in health and disease. Acta Neuropathol. 133, 665-704. doi: 10.1007/s00401-017-1707-9

Hampel, H., Vassar, R., De Strooper, B., Hardy, J., Willem, M., Singh, N., et al. (2021). The $\beta$-Secretase BACE1 in Alzheimer's disease. Biol. Psychiatry 89, 745-756. doi: 10.1016/j.biopsych.2020.02.001

Harvey, S. H., Sheedy, D. M., Cuddihy, A. R., and O'Connell, M. J. (2004) Coordination of DNA damage responses via the Smc5/Smc6 complex. Mol. Cell. Biol. 24, 662-674, doi: 10.1128/MCB.24.2.662-674.2004

Henstridge, C. M., Jackson, R. J., Kim, J. M., Herrmann, A. G., Wright, A. K., Harris, S. E., et al. (2015). Post-mortem brain analyses of the Lothian Birth Cohort 1936: extending lifetime cognitive and brain phenotyping to the level of the synapse. Acta Neuropathol. Commun. 3:53. doi: 10.1186/s40478-0150232-0

Huang, Z., Zhao, J., Wang, W., Zhou, J., and Zhang, J. (2020). Depletion of LncRNA NEAT1 rescues mitochondrial dysfunction through NEDD4Ldependent PINK1 degradation in animal models of Alzheimer's disease. Front. Cell. Neurosci. 14:28. doi: 10.3389/fncel.2020.00028

Iqbal, K., Liu, F., and Gong, C. X. (2016). Tau and neurodegenerative disease: the story so far. Nat. Rev. Neurol. 12, 15-27. doi: 10.1038/nrneurol.2015.225

Ji, P., Diederichs, S., Wang, W., Böing, S., Metzger, R., Schneider, P. M., et al. (2003). MALAT-1, a novel noncoding RNA, and thymosin beta4 predict metastasis and survival in early-stage non-small cell lung cancer. Oncogene 22, 8031-8041. doi: 10.1038/sj.onc.1206928 
Ji, Y., Lu, Y., Yang, F., Shen, W., Tang, T. T., Feng, L., et al. (2010). Acute and gradual increases in BDNF concentration elicit distinct signaling and functions in neurons. Nat. Neurosci. 13, 302-309. doi: 10.1038/nn.2505

Jia, L., Du, Y., Chu, L., Zhang, Z., Li, F., Lyu, D., et al. (2020). Prevalence, risk factors, and management of dementia and mild cognitive impairment in adults aged 60 years or older in China: a cross-sectional study. Lancet Public Health 5, e661-e671. doi: 10.1016/S2468-2667(20)30185-7

John, A., and Reddy, P. H. (2021). Synaptic basis of Alzheimer's disease: focus on synaptic amyloid beta, P-tau and mitochondria. Ageing Res. Rev. 65:101208. doi: 10.1016/j.arr.2020.101208

Jurado, S. (2017). AMPA receptor trafficking in natural and pathological aging. Front. Mol. Neurosci. 10:446. doi: 10.3389/fnmol.2017.00446

Kandalepas, P. C., and Vassar, R. (2014). The normal and pathologic roles of the Alzheimer's beta-secretase, BACE1. Curr. Alzheimer Res. 11, 441-449. doi: 10.2174/1567205011666140604122059

Kang, M. J., Abdelmohsen, K., Hutchison, E. R., Mitchell, S. J., Grammatikakis, I., Guo, R., et al. (2014). HuD regulates coding and noncoding $\mathrm{RNA}$ to induce $\mathrm{APP} \rightarrow \mathrm{A} \beta$ processing. Cell Rep. 7, 1401-1409. doi: 10.1016/j.celrep.2014.04.050

Karakas, D., and Ozpolat, B. (2021). The role of LncRNAs in translation. Noncoding RNA 7:16. doi: $10.3390 /$ ncrna7010016

Karch, C. M., and Goate, A. M. (2015). Alzheimer's disease risk genes and mechanisms of disease pathogenesis. Biol. Psychiatry 77, 43-51. doi: 10.1016/j.biopsych.2014.05.006

Kashyap, G., Bapat, D., Das, D., Gowaikar, R., Amritkar, R. E., Rangarajan, G., et al. (2019). Synapse loss and progress of Alzheimer's disease -A network model. Sci. Rep. 9:6555. doi: 10.1038/s41598-019-43076-y

Ke, S., Yang, Z., Yang, F., Wang, X., Tan, J., and Liao, B. (2019). Long noncoding RNA NEAT1 aggravates A $\beta$-induced neuronal damage by targeting miR-107 in Alzheimer's disease. Yonsei Med. J. 60, 640-650. doi: 10.3349/ymj.2019.60.7.640

Kickstein, E., Krauss, S., Thornhill, P., Rutschow, D., Zeller, R., Sharkey, J., et al. (2010). Biguanide metformin acts on tau phosphorylation via mTOR/protein phosphatase 2A (PP2A) signaling. Proc. Natl. Acad. Sci. U. S. A. 107, 21830-21835. doi: 10.1073/pnas.0912793107

Kobayashi, S., Wagatsuma, H., Ono, R., Ichikawa, H., Yamazaki, M., Tashiro, H., et al. (2000). Mouse Peg9/Dlk1 and human PEG9/DLK1 are paternally expressed imprinted genes closely located to the maternally expressed imprinted genes: mouse Meg3/Gtl2 and human MEG3. Genes Cells 5, 1029-1037. doi: 10.1046/j.1365-2443.2000.00390.x

Kuller, L. H., and Lopez, O. L. (2021). ENGAGE and EMERGE: truth and consequences? Alzheimers Dement. 17, 692-695. doi: 10.1002/alz.12286

Lane-Donovan, C., and Herz, J. (2017). ApoE, ApoE receptors, and the synapse in Alzheimer's disease. Trends Endocrinol. Metab. 28, 273-284. doi: 10.1016/j.tem.2016.12.001

Lassmann, H., Bancher, C., Breitschopf, H., Wegiel, J., Bobinski, M., Jellinger, K., et al. (1995). Cell death in Alzheimer's disease evaluated by DNA fragmentation in situ. Acta Neuropathol. 89, 35-41. doi: 10.1007/BF00294257

Ledda, F., Paratcha, G., Sandoval-Guzmán, T., and Ibáñez, C. F. (2007). GDNF and GFRalpha1 promote formation of neuronal synapses by ligand-induced cell adhesion. Nat. Neurosci. 10, 293-300. doi: 10.1038/nn1855

Leyns, C. E. G., and Holtzman, D. M. (2017). Glial contributions to neurodegeneration in tauopathies. Mol. Neurodegener. 12:50. doi: 10.1186/s13024-017-0192-x

Li, F., Wang, Y., Yang, H., Xu, Y., Zhou, X., Zhang, X., et al. (2019). The effect of BACE1-AS on $\beta$-amyloid generation by regulating BACE1 mRNA expression. BMC Mol. Biol. 20:23. doi: 10.1186/s12867-019-0140-0

Li, L., Xu, Y., Zhao, M., and Gao, Z. (2020a). Neuro-protective roles of long non-coding RNA MALAT1 in Alzheimer's disease with the involvement of the microRNA-30b/CNR1 network and the following PI3K/AKT activation. Exp. Mol. Pathol. 117:104545. doi: 10.1016/j.yexmp.2020.104545

Li, X., Wang, S. W., Li, X. L., Yu, F. Y., and Cong, H. M. (2020b). Knockdown of long non-coding RNA TUG1 depresses apoptosis of hippocampal neurons in Alzheimer's disease by elevating microRNA-15a and repressing ROCK1 expression. Inflamm. Res. 69, 897-910. doi: 10.1007/s00011-020-01364-8

Lim, J. W., Lee, J., and Pae, A. N. (2020). Mitochondrial dysfunction and Alzheimer's disease: prospects for therapeutic intervention. BMB Rep. 53, 47-55. doi: 10.5483/BMBRep.2020.53.1.279
Liu, T., Huang, Y., Chen, J., Chi, H., Yu, Z., Wang, J., et al. (2014). Attenuated ability of BACE1 to cleave the amyloid precursor protein via silencing long noncoding RNA BACE1-AS expression. Mol. Med. Rep. 10, 1275-1281. doi: $10.3892 / \mathrm{mmr} .2014 .2351$

Lloyd, A. G., Tateishi, S., Bieniasz, P. D., Muesing, M. A., Yamaizumi, M., and Mulder, L. C. (2006). Effect of DNA repair protein Rad18 on viral infection. PLoS Pathog. 2:e40. doi: 10.1371/journal.ppat.0020040

Lo, P. K., Wolfson, B., and Zhou, Q. (2016). Cellular, physiological and pathological aspects of the long non-coding RNA NEAT1. Front. Biol. 11, 413-426. doi: 10.1007/s11515-016-1433-z

Lopez-Font, I., Boix, C. P., Zetterberg, H., Blennow, K., and Sáez-Valero, J. (2019). Characterization of cerebrospinal fluid BACE1 species. Mol. Neurobiol. 56, 8603-8616. doi: 10.1007/s12035-019-01677-8

Lu, B., Nagappan, G., and Lu, Y. (2014). BDNF and synaptic plasticity, cognitive function, and dysfunction. Handb. Exp. Pharmacol. 220, 223-250. doi: 10.1007/978-3-642-45106-5_9

Luo, Q., and Chen, Y. (2016). Long noncoding RNAs and Alzheimer's disease. Clin. Interv. Aging 11, 867-872. doi: 10.2147/CIA.S107037

Ma, M., Xiong, W., Hu, F., Deng, M. F., Huang, X., Chen, J. G., et al. (2020). A novel pathway regulates social hierarchy via lncRNA AtLAS and postsynaptic synapsin IIb. Cell Res. 30, 105-118. doi: 10.1038/s41422-020-0273-1

Ma, P., Li, Y., Zhang, W., Fang, F., Sun, J., Liu, M., et al. (2019). Long noncoding RNA MALAT1 inhibits neuron apoptosis and neuroinflammation while stimulates neurite outgrowth and its correlation with MiR-125b mediates PTGS2, CDK5 and FOXQ1 in Alzheimer's disease. Curr. Alzheimer Res. 16, 596-612. doi: 10.2174/1567205016666190725130134

Maccioni, R. B., Navarrete, L. P., González, A., González-Canacer, A., GuzmánMartínez, L., and Cortés, N. (2020). Inflammation: a major target for compounds to control Alzheimer's disease. J. Alzheimers. Dis. 76, 1199-1213. doi: 10.3233/JAD-191014

Magistri, M., Velmeshev, D., Makhmutova, M., and Faghihi, M. A. (2015). Transcriptomics profiling of Alzheimer's disease reveal neurovascular defects, altered amyloid- $\beta$ homeostasis, and deregulated expression of long noncoding RNAs. J. Alzheimers. Dis. 48, 647-665. doi: 10.3233/JAD-150398

Martin, L., Latypova, X., Wilson, C. M., Magnaudeix, A., Perrin, M. L., and Terro, F. (2013a). Tau protein phosphatases in Alzheimer's disease: the leading role of PP2A. Ageing Res. Rev. 12, 39-49. doi: 10.1016/j.arr.2012.06.008

Martin, L., Latypova, X., Wilson, C. M., Magnaudeix, A., Perrin, M. L., Yardin, C., et al. (2013b). Tau protein kinases: involvement in Alzheimer's disease. Ageing Res. Rev. 12, 289-309. doi: 10.1016/j.arr.2012.06.003

Masoumi, F., Ghorbani, S., Talebi, F., Branton, W. G., Rajaei, S., Power, C., et al. (2019). Malat1 long noncoding RNA regulates inflammation and leukocyte differentiation in experimental autoimmune encephalomyelitis. $J$. Neuroimmunol. 328, 50-59. doi: 10.1016/j.jneuroim.2018.11.013

Massone, S., Ciarlo, E., Vella, S., Nizzari, M., Florio, T., Russo, C., et al. (2012). NDM29, a RNA polymerase III-dependent non coding RNA, promotes amyloidogenic processing of APP and amyloid $\beta$ secretion. Biochim. Biophys. Acta 1823, 1170-1177. doi: 10.1016/j.bbamcr.2012.05.001

Massone, S., Vassallo, I., Fiorino, G., Castelnuovo, M., Barbieri, F., Borghi, R., et al. (2011). 17A, a novel non-coding RNA, regulates GABA B alternative splicing and signaling in response to inflammatory stimuli and in Alzheimer disease. Neurobiol. Dis. 41, 308-317. doi: 10.1016/j.nbd.2010.09.019

Meng, J., Ding, T., Chen, Y., Long, T., Xu, Q., Lian, W., et al. (2021). LncRNA-Meg3 promotes Nlrp3-mediated microglial inflammation by targeting miR-7a-5p. Int. Immunopharmacol. 90:107141. doi: 10.1016/j.intimp.2020.107141

Mercer, T. R., Dinger, M. E., and Mattick, J. S. (2009). Long non-coding RNAs: insights into functions. Nat. Rev. Genet. 10, 155-159. doi: 10.1038/nrg2521

Mills, J. D., Ward, M., Chen, B. J., Iyer, A. M., Aronica, E., and Janitz, M. (2016). LINC00507 is specifically expressed in the primate cortex and has age-dependent expression patterns. J. Mol. Neurosci. 59, 431-439. doi: 10.1007/s12031-016-0745-4

Moir, R. D., Lathe, R., and Tanzi, R. E. (2018). The antimicrobial protection hypothesis of Alzheimer's disease. Alzheimers Dement. 14, 1602-1614. doi: 10.1016/j.jalz.2018.06.3040

Morris, G. P., Clark, I. A., and Vissel, B. (2014). Inconsistencies and controversies surrounding the amyloid hypothesis of Alzheimer's disease. Acta Neuropathol. Commun. 2:135. doi: 10.1186/s40478-014-0135-5 
Muddashetty, R., Khanam, T., Kondrashov, A., Bundman, M., Iacoangeli, A., Kremerskothen, J., et al. (2002). Poly(A)-binding protein is associated with neuronal BC1 and BC200 ribonucleoprotein particles. J. Mol. Biol. 321, 433-445. doi: 10.1016/S0022-2836(02)00655-1

Mullard, A. (2021). Landmark Alzheimer's drug approval confounds research community. Nature 594, 309-310. doi: 10.1038/d41586-021-01546-2

Mus, E., Hof, P. R., and Tiedge, H. (2007). Dendritic BC200 RNA in aging and in Alzheimer's disease. Proc. Natl. Acad. Sci. U. S. A. 104, 10679-10684. doi: $10.1073 /$ pnas. 0701532104

Muslimov, I. A., Santi, E., Homel, P., Perini, S., Higgins, D., and Tiedge, H. (1997). RNA transport in dendrites: a cis-acting targeting element is contained within neuronal BC1 RNA. J. Neurosci. 17, 4722-4733. doi: 10.1523/JNEUROSCI.17-12-04722.1997

Nisbet, R. M., Polanco, J. C., Ittner, L. M., and Götz, J. (2015). Tau aggregation and its interplay with amyloid- $\beta$. Acta Neuropathol. 129, 207-220. doi: 10.1007/s00401-014-1371-2

Nisticò, R., Pignatelli, M., Piccinin, S., Mercuri, N. B., and Collingridge, G. (2012). Targeting synaptic dysfunction in Alzheimer's disease therapy. Mol. Neurobiol. 46, 572-587. doi: 10.1007/s12035-012-8324-3

Nussbaum, J. M., Schilling, S., Cynis, H., Silva, A., Swanson, E., Wangsanut, T., et al. (2012). Prion-like behaviour and tau-dependent cytotoxicity of pyroglutamylated amyloid- $\beta$. Nature 485, 651-655. doi: 10.1038/nature 11060

Palop, J. J., and Mucke, L. (2010). Amyloid-beta-induced neuronal dysfunction in Alzheimer's disease: from synapses toward neural networks. Nat. Neurosci. 13, 812-818. doi: $10.1038 / \mathrm{nn} .2583$

Parenti, R., Paratore, S., Torrisi, A., and Cavallaro, S. (2007). A natural antisense transcript against Rad18, specifically expressed in neurons and upregulated during beta-amyloid-induced apoptosis. Eur. J. Neurosci. 26, 2444-2457. doi: 10.1111/j.1460-9568.2007.05864.x

Pereira, J. B., Janelidze, S., Ossenkoppele, R., Kvartsberg, H., Brinkmalm, A., Mattsson-Carlgren, N., et al. (2021). Untangling the association of amyloid$\beta$ and tau with synaptic and axonal loss in Alzheimer's disease. Brain 144, 310-324. doi: 10.1093/brain/awaa395

Perez Ortiz, J. M., and Swerdlow, R. H. (2019). Mitochondrial dysfunction in Alzheimer's disease: role in pathogenesis and novel therapeutic opportunities. Br. J. Pharmacol. 176, 3489-3507. doi: 10.1111/bph.14585

Petukhova, E. O., Mukhamedshina, Y. O., Salafutdinov, I. I., Garanina, E. E., Kaligin, M. S., Leushina, A. V., et al. (2019). Effects of transplanted umbilical cord blood mononuclear cells overexpressing GDNF on spatial memory and hippocampal synaptic proteins in a mouse model of Alzheimer's disease. J. Alzheimers. Dis. 69, 443-453. doi: 10.3233/JAD-190150

Pooler, A. M., Noble, W., and Hanger, D. P. (2014). A role for tau at the synapse in Alzheimer's disease pathogenesis. Neuropharmacology 76, 1-8. doi: 10.1016/j.neuropharm.2013.09.018

Qian, M. C., Liu, J., Yao, J. S., Wang, W. M., Yang, J. H., Wei, L. L., et al. (2015). Caspase- 8 mediates amyloid- $\beta$-induced apoptosis in differentiated PC12 cells. J. Mol. Neurosci. 56, 491-499. doi: 10.1007/s12031-015-0498-5

Ransohoff, J. D., Wei, Y., and Khavari, P. A. (2018). The functions and unique features of long intergenic non-coding RNA. Nat. Rev. Mol. Cell Biol. 19, 143-157. doi: 10.1038/nrm.2017.104

Sager, K. L., Wuu, J., Leurgans, S. E., Rees, H. D., Gearing, M., Mufson, E. J., et al. (2007). Neuronal LR11/sorLA expression is reduced in mild cognitive impairment. Ann. Neurol. 62, 640-647. doi: 10.1002/ana.21190

Scheltens, P., Blennow, K., Breteler, M. M., de Strooper, B., Frisoni, G. B., Salloway, S., et al. (2016). Alzheimer's disease. Lancet 388, 505-517. doi: 10.1016/S0140-6736(15)01124-1

Selkoe, D. J. (2002). Alzheimer's disease is a synaptic failure. Science 298, 789-791. doi: 10.1126/science. 1074069

Serý, O., Povová, J., Míšek, I., Pešák, L., and Janout, V. (2013). Molecular mechanisms of neuropathological changes in Alzheimer's disease: a review. Folia Neuropathol. 51, 1-9. doi: 10.5114/fn.2013.34190

Shen, Y., Wang, H., Sun, Q., Yao, H., Keegan, A. P., Mullan, M., et al. (2018). Increased plasma beta-secretase 1 may predict conversion to alzheimer's disease dementia in individuals with mild cognitive impairment. Biol. Psychiatry 83, 447-455. doi: 10.1016/j.biopsych.2017.02.007

Shin, H., Lee, J., Kim, Y., Jang, S., Lee, Y., Kim, S., et al. (2017). Knockdown of BC200 RNA expression reduces cell migration and invasion by destabilizing
mRNA for calcium-binding protein S100A11. RNA Biol. 14, 1418-1430. doi: 10.1080/15476286.2017.1297913

Sofroniew, M. V., and Vinters, H. V. (2010). Astrocytes: biology and pathology. Acta Neuropathol. 119, 7-35. doi: 10.1007/s00401-009-0619-8

Soria Lopez, J. A., Gonzalez, H. M., and Leger, G. C. (2019). Alzheimer's disease. Handb. Clin. Neurol. 167, 231-255. doi: 10.1016/B978-0-12-804766-8.00013-3

Sosińska, P., Mikuła-Pietrasik, J., and Ksiazek, K. (2015). The double-edged sword of long non-coding RNA: The role of human brain-specific BC200 RNA in translational control, neurodegenerative diseases, and cancer. Mutat. Res. Rev. Mutat. Res. 766, 58-67. doi: 10.1016/j.mrrev.2015.08.002

Statello, L., Guo, C. J., Chen, L. L., and Huarte, M. (2021). Gene regulation by long non-coding RNAs and its biological functions. Nat. Rev. Mol. Cell Biol. 22, 96-118, doi: 10.1038/s41580-020-00315-9

Straten, G., Eschweiler, G. W., Maetzler, W., Laske, C., and Leyhe, T. (2009). Glial cell-line derived neurotrophic factor (GDNF) concentrations in cerebrospinal fluid and serum of patients with early Alzheimer's disease and normal controls. J. Alzheimers. Dis. 18, 331-337. doi: 10.3233/JAD-2009-1146

Strausberg, R. L., Feingold, E. A., Grouse, L. H., Derge, J. G., Klausner, R. D., Collins, F. S., et al. (2002). Generation and initial analysis of more than 15,000 full-length human and mouse cDNA sequences. Proc. Natl. Acad. Sci. U. S. A. 99, 16899-16903. doi: 10.1073/pnas.242603899

Sunwoo, J. S., Lee, S. T., Im, W., Lee, M., Byun, J. I., Jung, K. H., et al. (2017). Altered expression of the long noncoding RNA NEAT1 in Huntington's disease. Mol. Neurobiol. 54, 1577-1586. doi: 10.1007/s12035-016-9928-9

Tateishi, S., Sakuraba, Y., Masuyama, S., Inoue, H., and Yamaizumi, M. (2000). Dysfunction of human Rad18 results in defective postreplication repair and hypersensitivity to multiple mutagens. Proc. Natl. Acad. Sci. U. S. A. 97, 7927-7932. doi: 10.1073/pnas.97.14.7927

Thal, D. R., and Fandrich, M. (2015). Protein aggregation in Alzheimer's disease: abeta and tau and their potential roles in the pathogenesis of AD. Acta Neuropathol. 129, 163-165. doi: 10.1007/s00401-015-1387-2

Toska, E., and Roberts, S. G. (2014). Mechanisms of transcriptional regulation by WT1 (Wilms' tumour 1). Biochem. J. 461, 15-32. doi: 10.1042/BJ20131587

Tyumentsev, M. A., Stefanova, N. A., Muraleva, N. A., Rumyantseva, Y. V., Kiseleva, E., Vavilin, V. A., et al. (2018). Mitochondrial dysfunction as a predictor and driver of Alzheimer's disease-like pathology in OXYS rats. $J$. Alzheimers. Dis. 63, 1075-1088. doi: 10.3233/JAD-180065

Ulland, T. K., and Colonna, M. (2018). TREM2 - a key player in microglial biology and disease. Nat. Rev. Neurol. 14, 667-675. doi: 10.1038/s41582-018-0072-1

Ventriglia, M., Zanardini, R., Bonomini, C., Zanetti, O., Volpe, D., Pasqualetti, P., et al. (2013). Serum brain-derived neurotrophic factor levels in different neurological diseases. Biomed. Res. Int. 2013:901082. doi: 10.1155/2013/901082

Verheijen, J., Van den Bossche, T., van der Zee, J., Engelborghs, S., SanchezValle, R., Llad,ó, A., et al. (2016). A comprehensive study of the genetic impact of rare variants in SORL1 in European early-onset Alzheimer's disease. Acta Neuropathol. 132, 213-224. doi: 10.1007/s00401-016-1566-9

Wang, H., Lu, B., and Chen, J. (2019a). Knockdown of lncRNA SNHG1 attenuated $A \beta(25-35)$-inudced neuronal injury via regulating KREMEN1 by acting as a ceRNA of miR-137 in neuronal cells. Biochem. Biophys. Res. Commun. 518, 438-444. doi: 10.1016/j.bbrc.2019.08.033

Wang, Q., Ge, X., Zhang, J., and Chen, L. (2020). Effect of IncRNA WT1AS regulating WT1 on oxidative stress injury and apoptosis of neurons in Alzheimer's disease via inhibition of the miR-375/SIX4 axis. Aging 12, 23974-23995. doi: 10.18632/aging.104079

Wang, X., Zhang, M., and Liu, H. (2019b). LncRNA17A regulates autophagy and apoptosis of SH-SY5Y cell line as an in vitro model for Alzheimer's disease. Biosci. Biotechnol. Biochem. 83, 609-621. doi: 10.1080/09168451.2018.1562874

Willnow, T. E., Carlo, A. S., Rohe, M., and Schmidt, V. (2010). SORLA/SORL1, a neuronal sorting receptor implicated in Alzheimer's disease. Rev. Neurosci. 21, 315-329. doi: 10.1515/REVNEURO.2010.21.4.315

Wu, C., Yang, J., Li, R., Lin, X., Wu, J., and Wu, J. (2021). LncRNA WT1AS/miR-494-3p regulates cell proliferation, apoptosis, migration and invasion via PTEN/PI3K/AKT signaling pathway in non-small cell lung cancer. Onco. Targets. Ther. 14, 891-904. doi: 10.2147/OTT.S278233

Wu, P., Zuo, X., Deng, H., Liu, X., Liu, L., and Ji, A. (2013). Roles of long noncoding RNAs in brain development, functional diversification and neurodegenerative diseases. Brain Res. Bull. 97, 69-80. doi: 10.1016/j.brainresbull.2013.06.001 
Yan, Y., Yan, H., Teng, Y., Wang, Q., Yang, P., Zhang, L., et al. (2020). Long non-coding RNA 00507/miRNA-181c-5p/TTBK1/MAPT axis regulates tau hyperphosphorylation in Alzheimer's disease. J. Gene Med. 22:e3268. doi: 10.1002/jgm.3268

Yan, L. J., Xiao, M., Chen, R., and Cai, Z. (2013). Metabolic dysfunction of astrocyte: an initiating factor in beta-amyloid pathology? Aging Neurodegener $1,7-14$.

Yi, J., Chen, B., Yao, X., Lei, Y., Ou, F., and Huang, F. (2019). Upregulation of the lncRNA MEG3 improves cognitive impairment, alleviates neuronal damage, and inhibits activation of astrocytes in hippocampus tissues in Alzheimer's disease through inactivating the PI3K/Akt signaling pathway. J. Cell. Biochem. 120, 18053-18065. doi: 10.1002/jcb.29108

Yue, D., Guanqun, G., Jingxin, L., Sen, S., Shuang, L., Yan, S., et al. (2020). Silencing of long noncoding RNA XIST attenuated Alzheimer's disease-related BACE1 alteration through miR-124. Cell Biol. Int. 44, 630-636. doi: 10.1002/c bin. 11263

Zalfa, F., Adinolfi, S., Napoli, I., Kühn-Hölsken, E., Urlaub, H., Achsel, T., et al. (2005). Fragile X mental retardation protein (FMRP) binds specifically to the brain cytoplasmic RNAs BC1/BC200 via a novel RNA-binding motif. J. Biol. Chem. 280, 33403-33410. doi: 10.1074/jbc.M504286200

Zempel, H., and Mandelkow, E. M. (2015). Tau missorting and spastininduced microtubule disruption in neurodegeneration: Alzheimer disease and hereditary spastic paraplegia. Mol. Neurodegener. 10:68. doi: 10.1186/s13024-015-0064-1

Zeng, T., Ni, H., Yu, Y., Zhang, M., Wu, M., Wang, Q., et al. (2019). BACE1AS prevents BACE1 mRNA degradation through the sequestration of BACE1-targeting miRNAs. J. Chem. Neuroanat. 98, 87-96. doi: 10.1016/j.jchemneu.2019.04.001

Zhang, Q., Hu, C., Huang, J., Liu, W., Lai, W., Leng, F., et al. (2019a). ROCK1 induces dopaminergic nerve cell apoptosis via the activation of Drp1-mediated aberrant mitochondrial fission in Parkinson's disease. Exp. Mol. Med. 51, 1-13. doi: 10.1038/s12276-019-0318-Z

Zhang, T., Pang, P., Fang, Z., Guo, Y., Li, H., Li, X., et al. (2018a). Expression of BC1 impairs spatial learning and memory in Alzheimer's disease via APP translation. Mol. Neurobiol. 55, 6007-6020. doi: 10.1007/s12035-01 7-0820-z

Zhang, W., Zhao, H., Wu, Q., Xu, W., and Xia, M. (2018b). Knockdown of BACE1-AS by siRNA improves memory and learning behaviors in Alzheimer's disease animal model. Exp. Ther. Med. 16, 2080-2086. doi: 10.3892/etm.201 8.6359

Zhang, X., Wang, W., Zhu, W., Dong, J., Cheng, Y., Yin, Z., et al. (2019b). Mechanisms and functions of long non-coding RNAs at multiple regulatory levels. Int. J. Mol. Sci. 20:5573. doi: 10.3390/ijms20225573

Zhao, J., Fu, Y., Yamazaki, Y., Ren, Y., Davis, M. D., Liu, C. C., et al. (2020a). APOE4 exacerbates synapse loss and neurodegeneration in Alzheimer's disease patient iPSC-derived cerebral organoids. Nat. Commun. 11:5540. doi: 10.1038/s41467-020-19264-0

Zhao, M. Y., Wang, G. Q., Wang, N. N., Yu, Q. Y., Liu, R. L., and Shi, W. Q. (2019). The long-non-coding RNA NEAT1 is a novel target for Alzheimer's disease progression via miR-124/BACE1 axis. Neurol. Res. 41, 489-497. doi: 10.1080/01616412.2018. 1548747
Zhao, N., Liu, C. C., Qiao, W., and Bu, G. (2018). Apolipoprotein E, receptors, and modulation of Alzheimer's disease. Biol. Psychiatry 83, 347-357. doi: 10.1016/j.biopsych.2017.03.003

Zhao, Y., Wang, Z., Mao, Y., Li, B., Zhu, Y., Zhang, S., et al. (2020b). NEAT1 regulates microtubule stabilization via FZD3/GSK3 $\beta / P$-tau pathway in SH-SY5Y cells and APP/PS1 mice. Aging 12, 23233-23250. doi: 10.18632/aging.104098

Zhong, J., Jiang, L., Huang, Z., Zhang, H., Cheng, C., Liu, H., et al. (2017). The long non-coding RNA Neat1 is an important mediator of the therapeutic effect of bexarotene on traumatic brain injury in mice. Brain Behav. Immun. 65, 183-194. doi: 10.1016/j.bbi.2017.05.001

Zhou, B., Li, L., Qiu, X., Wu, J., Xu, L., and Shao, W. (2020). Long noncoding RNA ANRIL knockdown suppresses apoptosis and pro-inflammatory cytokines while enhancing neurite outgrowth via binding microRNA-125a in a cellular model of Alzheimer's disease. Mol. Med. Rep. 22, 1489-1497. doi: $10.3892 / \mathrm{mmr} .2020 .11203$

Zhou, H. J., Wang, L. Q., Wang, D. B., Yu, J. B., Zhu, Y., Xu, Q. S., et al. (2018a). Long noncoding RNA MALAT1 contributes to inflammatory response of microglia following spinal cord injury via the modulation of a miR199b/IKKß/NF-кB signaling pathway. Am. J. Physiol. Cell Physiol. 315, C52c61. doi: 10.1152/ajpcell.00278.2017

Zhou, K., Zhang, C., Yao, H., Zhang, X., Zhou, Y., Che, Y., et al. (2018b). Knockdown of long non-coding RNA NEAT1 inhibits glioma cell migration and invasion via modulation of SOX2 targeted by miR-132. Mol. Cancer 17:105 doi: 10.1186/s12943-018-0849-2

Zhou, S., Yu, X., Wang, M., Meng, Y., Song, D., Yang, H., et al. (2021). Long noncoding RNAs in pathogenesis of neurodegenerative diseases. Front. Cell Dev. Biol. 9, 1219-1231. doi: 10.3389/fcell.2021.719247

Zhuang, J., Cai, P., Chen, Z., Yang, Q., Chen, X., Wang, X., et al (2020). Long noncoding RNA MALAT1 and its target microRNA-125b are potential biomarkers for Alzheimer's disease management via interactions with FOXQ1, PTGS2 and CDK5. Am. J. Transl. Res. 12, 5940-5954. doi: $10.3389 /$ fncel.2020.587747

Conflict of Interest: The authors declare that the research was conducted in the absence of any commercial or financial relationships that could be construed as a potential conflict of interest.

Publisher's Note: All claims expressed in this article are solely those of the authors and do not necessarily represent those of their affiliated organizations, or those of the publisher, the editors and the reviewers. Any product that may be evaluated in this article, or claim that may be made by its manufacturer, is not guaranteed or endorsed by the publisher.

Copyright (c) 2022 Lan, Chen, Jin, Xu and Zhu. This is an open-access article distributed under the terms of the Creative Commons Attribution License (CC BY). The use, distribution or reproduction in other forums is permitted, provided the original author(s) and the copyright owner(s) are credited and that the original publication in this journal is cited, in accordance with accepted academic practice. No use, distribution or reproduction is permitted which does not comply with these terms. 